\title{
Analysis of Limb segment length to the total body height among the undergraduate students in a medical college of Nepal
}

\author{
Muna Kadel ${ }^{1}$, Shanta Hada ${ }^{2}$, Shambhu Nath Pant ${ }^{3}$ \\ ${ }^{1}$ Associate Professor, Department of Anatomy, Nepalese Army Institute of Health Sciences, Sanobharyang, \\ Kathmandu, Nepal, 'Lecturer, Department of Anatomy, KIST Medical College, Lalitpur, Nepal, ${ }^{3}$ Professor, Department \\ of Community Medicine, Nepalese Army Institute of Health Sciences, Kathmandu, Nepal
}

Background: Total body height is important for calculating body mass index, drug dosages calculations and other patient care issues. Total height estimation from different body measurements are surrogate measures of stature which is very useful when only fragmentary remains of a human body are found. Aims and Objective: The aim of this study is to develop the relationship of total body height with arm span, leg length and trunk length in Nepalese Medical students. Materials and Methods: A descriptive cross-sectional study was conducted in 441 medical students in the Department of Anatomy, KIST Medical College and Teaching Hospital, Lalitpur, Nepal from January to June 2019 after taking ethical approval. Body height, arm span, leg length and trunk length were measured and regression and correlation analysis between them were done. Results: The mean standing height, arm span, trunk length and leg length were $161.85 \pm 9.14,165.37 \pm 10.5,84.80 \pm 4.23,77.06 \pm 6.5 \mathrm{~cm}$ respectively. Correlation coefficient of standing height with arm span, trunk length and leg length were $0.87,0.76$ and 0.90 respectively. Regression coefficient for standing height and trunk length, standing height and arm span and standing height and leg length were 1.65, 0.76 and 1.27 respectively. Regression equations for standing height were determined. Conclusions: Total body height shows strong correlation with arm span, trunk length and leg length.

Key words: Arm; Body height; Body mass index; Leg; Regression analysis

\section{INTRODUCTION}

Total body height is defined as the vertical distance from the heel to the vertex in a subject standing erect. Measurements of standing height in elderly people, bedridden patients, and the people with skeletal deformity is difficult. ${ }^{1}$

Obtaining standing height is important for calculating body mass index, pulmonary function, drug dosages calculations, renal clearances, and other patient care issues. ${ }^{2}$ Total height estimation from different body measurements such as arm span, leg length and trunk length are surrogate measures of stature which is very useful in the establishment of the identity of an individual when only fragmentary remains of a human body is found. ${ }^{3,4}$
The relationship between limb segments and total height varies across the populations which show the need for the development of population-specific correlation equations. ${ }^{5}$ So, this study aimed to develop the relationship of total body height with arm span, leg length and trunk length in the students of a Medical College of Nepal.

\section{MATERIALS AND METHODS}

A cross-sectional observational study was conducted among the undergraduate students of KIST Medical College from January 2019 to June 2019 after getting ethical approval from the Institutional Review Committee of KIST Medical College. All the participants were informed about the objectives of the study and verbal consent was 
taken. The list of MBBS and BDS students was obtained from the academic section of the college and the samples were chosen using computer generated random numbers. Based on the study of, Digssie A et al.(2018) ${ }^{1}$ sample size was calculated using formula $n=Z^{2} \sigma^{2} / d^{2}(n=$ sample size, $Z=1.96$ at $95 \%$ confidence interval, Standard deviation of 9.20 and margin of error of $1 \mathrm{~cm}$ ). The sample size was calculated as 325 and a total of 441 students were included.

Individuals with skeletal deformities, past history of skeletal injuries or bone disease were excluded from the study. Standing height was measured by stadiometer recorded to the nearest $0.1 \mathrm{~cm}$. During the measurement, head of participants was kept in a Frankfurt Plane, knees straight, and the heels, buttocks, and the shoulders blades touching the vertical surface of the stadiometer with bare foot.

Sitting height was measured after sitting on standard laboratory stool of known height placed against the stadiometer. Then, trunk length was obtained by subtracting the height of stool from reading of the stadiometer.

Leg length was calculated as the difference between standing height and trunk length. Arm span was measured with steel tape from the tip of the middle finger on one hand to the tip of the middle finger on the other hand with the individual leaning against the wall with both arms abducted at $90^{\circ}$.

The data was collected, tabulated and the analysis was carried out using SPSS version-24. Mean and standard deviations were obtained for different anthropometric variables. The relationships between body height, arm span, leg length and trunk length were determined using simple correlation coefficients. Then a linear regression analysis was performed to examine the extent to which arm span, trunk length and leg length can reliably predict body height. Finally, these relationships were plotted as scatter diagram.

$P$ values $<0.05$ were considered as statistically significant.

\section{RESULTS}

The results for the standing height, trunk length, leg length and arm span of total populations are shown in Tables 1.

Out of 421 students, the study population comprised of $179(42.5 \%)$ males and $242(57.5 \%)$ females with the mean age of $19.80 \pm 1.32$ years. The mean standing height, arm span, trunk length and leg length were 161.85 \pm 9.14 , $165.37 \pm 10.5,84.80 \pm 4.23,77.06 \pm 6.5 \mathrm{~cm}$ respectively. The mean standing height was $4 \mathrm{~cm}$ less than the arm span. The mean standing height, arm span, trunk length and leg length in male were $169.0 \pm 7.3,174.57 \pm 7.479$, $87.62 \pm 3.36,81.4 \pm 5.9 \mathrm{~cm}$ respectively. In female, the mean standing height, arm span, trunk length and leg length were $156.56 \pm 6.26,158.57 \pm 6.483,82.71 \pm 3.56,73.85 \pm 4.85 \mathrm{~cm}$

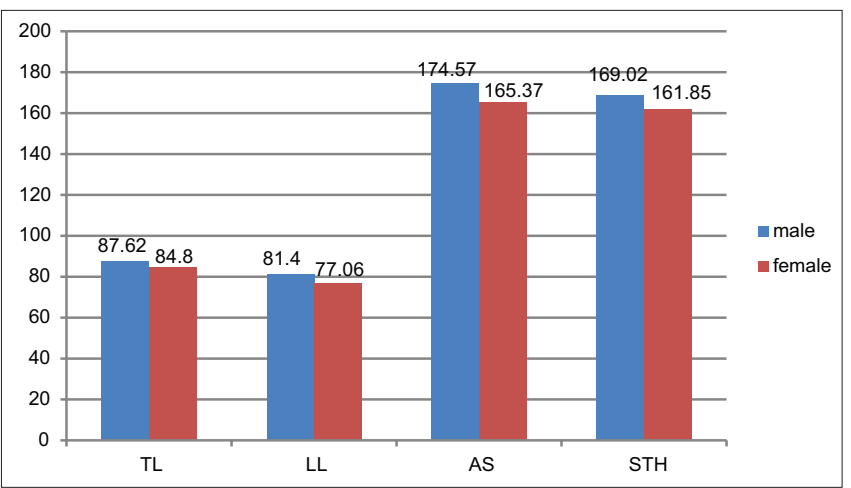

Figure 1: Histogram comparing the means of different parameters. (TL- Trunk Length, LL-Leg Length, AS- Arm Span, STH- Standing height)

Table 1: Descriptive Statistics in relation to age, standing height, trunk length, leg length and arm span

\begin{tabular}{lcccc} 
Variables & Minimum & Maximum & Mean & Std. Deviation \\
\hline Age (years) & 17 & 25 & 19.80 & 1.315 \\
Standing Height $(\mathrm{cm})$ & 126 & 184 & 161.85 & 9.148 \\
Trunk Length $(\mathrm{cm})$ & 75 & 103 & 84.80 & 4.238 \\
Leg Length $(\mathrm{cm})$ & 41 & 98 & 77.06 & 6.500 \\
Arm Span $(\mathrm{cm})$ & 142 & 200 & 165.37 & 10.515 \\
\hline
\end{tabular}

Table 2: Correlation and linear regression analysis and between standing height and different variables

\begin{tabular}{|c|c|c|c|c|c|c|}
\hline \multirow[t]{2}{*}{ Variables } & \multicolumn{4}{|c|}{ Regression analysis } & \multicolumn{2}{|c|}{ Correlation analysis } \\
\hline & Regression coefficient & $P$ value & R-square(\%) & Constant & Correlation coefficient & $P$ value \\
\hline $\begin{array}{l}\text { Standing height } \\
\text { and trunk length }\end{array}$ & 1.653 & 0.000 & 58.6 & 21.677 & 0.766 & 0.000 \\
\hline $\begin{array}{l}\text { Standing height } \\
\text { and arm span }\end{array}$ & 0.759 & & 76.1 & 36.271 & 0.873 & \\
\hline $\begin{array}{l}\text { Standing height } \\
\text { and leg length }\end{array}$ & 1.278 & & 82.4 & 63.407 & 0.908 & \\
\hline
\end{tabular}




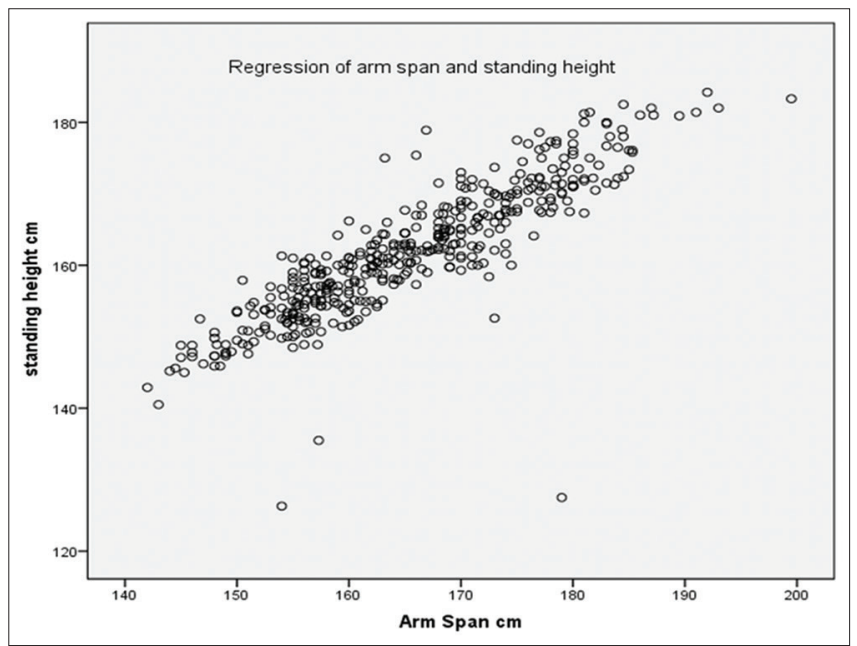

AQ1 Figure 2: Scatter diagram showing relationship between arm span and standing height

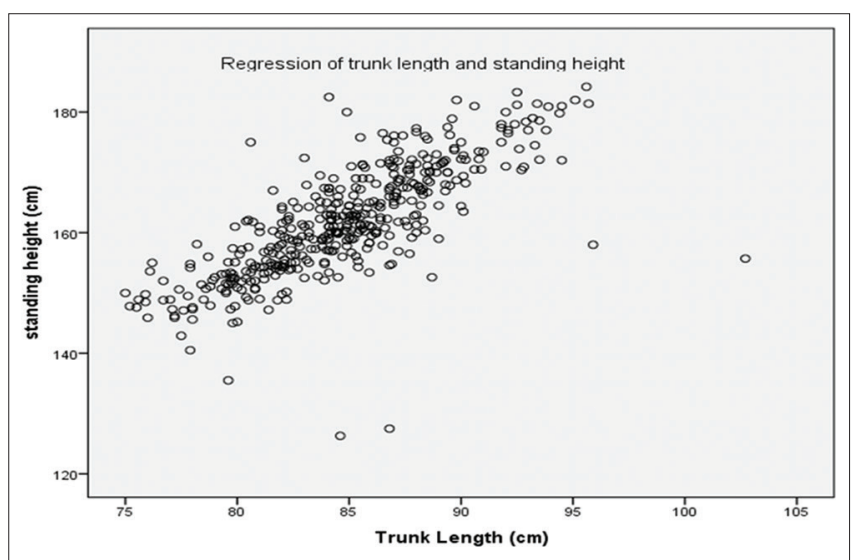

AQ1 Figure 3: Scatter diagram showing relationship of trunk length and standing height

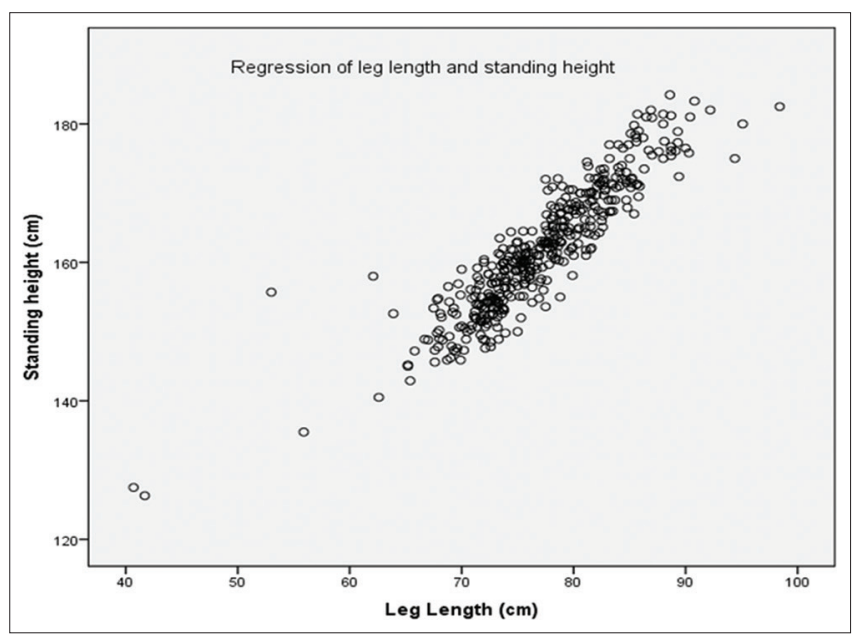

AQ1 Figure 4: Scatter diagram showing relationship between leg length and standing height

respectively shown in the Figure 1. The means of different parameters between male and female were statistically significant $(\mathrm{P}<0.000)$.
The results of linear regression analysis and correlation coefficients are shown in Table 2. The estimated regression equations for standing height were obtained as:

Standing height $(\mathrm{cm})=36.271+0.76$ Arm span $(\mathrm{cm})$

Standing height $(\mathrm{cm})=21.677+1.65$ trunk length $(\mathrm{cm})$

Standing height $(\mathrm{cm})=63.407+1.278$ leg length $(\mathrm{cm})$.

\section{DISCUSSION}

When the accurate measurement for stature is unobtainable, it is necessary to use other surrogates. Several studies have been done to estimate the standing height using different anthropometric parameters like arm span, length of ulna, nasal length, length of foot and craniometric measurements in a variety of populations. ${ }^{3,5-8}$ So this study tried to establish the correlation between stature and different parameters like arm span, leg length and trunk length. Regression equations were then developed to predict stature.

The arm span was nearly 4 centimeters more than the body height in this study which is similar to the white and Nigerian population. Correlation of arm-span and height for Black subjects was 0.852 which is almost same as the finding of this study $(0.87) .{ }^{9}$

Leg length of South Indian woman is comparable to the leg length of female Nepalese Medical student in this study $(73.8 \mathrm{~cm}) .{ }^{5}$ Poor childhood health, insufficient diet, adverse family circumstances and maternal smoking during pregnancy are each known to reduce leg length. ${ }^{10}$ This study showed the positive correlation between length and standing height. The correlation and regression coefficient for standing height and leg length were 0.90 and 1.27 respectively. These findings were similar to the findings of Mohanty SP et al. in which the correlation and regression coefficient values were 0.84 and 1.24 respectively. ${ }^{5}$

This study showed the positive correlation between trunk length and total height. In 17 years Brazilian males, trunk length was $96 \mathrm{~cm}$ which is slightly more than that of Nepalese male Medical student which is $87.6 \mathrm{~cm} .{ }^{11}$

\section{LIMITATIONS}

In this study, ethnic or regional specific values for different parameters were not derived. So, further studies can be done with larger samples including different ethnic groups of Nepal.

\section{CONCLUSION}

Standing height shows strong correlations with arm span, trunk length and leg length. Any of these anthropometric 
parameters can be used to calculate the standing height by using above mentioned regression equation.

\section{AQ2 ACKNOWLEDGEMENT}

KIST Medical College.

\section{REFERENCES}

1. Digssie A, Argaw A and Belachew T. Developing an equation for estimating body height from linear body measurements of Ethiopian adults. J Physiol Anthropol 2018;37(1):26.

2. Lahner CR, Kassier SM and Veldman FJ. Estimation of true height: a study in population-specific methods among young South African adults. Public Health Nutr 2017;20 (2):210-219.

3. Mansur DI, Haque MK, Sharma K, Karki RK, Khanal K and Karna R. Estimation of Stature from Foot Length in Adult Nepalese Population and its Clinical Relevance. Kathmandu Univ Med J 2012: 37(1):16-19.

4. Chittawatanarat K, Pruenglampoo S, Trakulhoon V, Unginitpong $\mathrm{W}$ and Patumanond J. Height prediction from anthropometric length parameters in Thai people. Asia Pac J Clin Nutr 2012; 21(3):347-354.

5. Mohanty SP, Babu SS and Nair NS. The use of arm span as a predictor of height: a study of south Indian women. J Orthop Surg (Hong Kong) 2001; 9(1):19-23.

6. Madden AM, Tsikoura T and Stott DJ. The estimation of body height from ulna length in healthy adults from different ethnic groups. J Hum Nutr Diet 2011; 25(2):121-128.

7. Shrestha RN, Banstola D, Nepal D and Baral P. Estimation of stature from nasal length. Journal of Nepal Medical Association 2016; 55(204):76-78.

8. Shrestha R, Shrestha PK, Wasti $\mathrm{H}$, Kadel T, Kanchan $\mathrm{T}$ and Krishan K. Craniometric analysis for estimation of stature in Nepalese population- A study on autopsy sample. Forensic Sci Int 2015;(248):187.e1-187e6.

9. Steele MF and Chenier TC. Arm-span, height, and age in black and white women. Ann Hum Biol 1990; 17(6):533-541.

10. Bogin B and Varela-Silva MI. Leg Length, Body Proportion, and Health: a Review with a Note on Beauty. Int J Environ Res Public Health 2010; 7(3):1047-1075.

11. Gigante DP, Nazmi A, Lima RC, Barros FC and Victora CG. Epidemiology of early and late growth in height, leg and trunk length: findings from a birth cohort of Brazilian males. Eur J Clin Nutr 2009; 63(3):375-381.

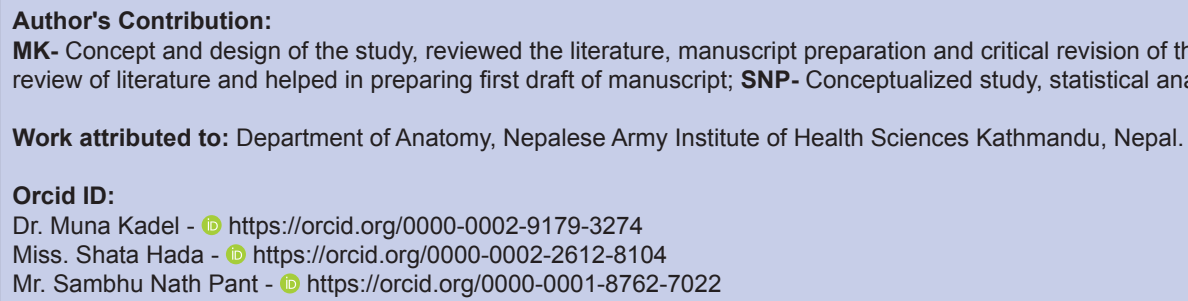

Author Query???

AQ1:Kindly cite Figures 2-4

AQ2: Kindly check acknowledgement text part 